\title{
Os prestadores de cuidados e competência no cuidado de suas famílias
}

\author{
Olga Marina Vega-Angarita*
}

\section{RESUMO}

Objetivo: descrever o perfil demográfico e da competência dos cuidadores familiares de pessoas afetadas por doenças crónicas. Materiais e Métodos: estudo quantitativo, descritivo transversal foi realizado em 200 cuidadores familiares de residentes doentes crónicos da área de influência de uma instituição que presta jardas do distrito de saúde primários. Na medição das características sócio demográficas foi utilizado instrumento Grupo Crônica Care Paciente, Universidade Nacional, Groomer, e a avaliação da concorrência Competitivo Instrumento Care-cuidador (versão resumida). Resultados: sociodemográficas e da concorrência na participação nos resultados são descritos. A maior valorização dos cuidadores em conhecimento, singularidade, categorias instrumentais e antecipação encontrado; mas não em tamanho e desfrutar de relações sociais e interação. Conclusões: reconhecendo a competência como um elemento essencial para o desempenho do cuidado, é um aspecto da análise de desempenho, novas maneiras de abordar a pessoa e seu cuidador.

PALAVRAS-CHAVE: cuidadores, doença crônica, enfermagem ${ }^{* *}$.

\footnotetext{
*Enfermeira.

Magister

Enfermagem

crônica Assistência ao Paciente. Professor Titular.

Universidad

Francisco de

Paula Santander.

Cúcuta, Colombia.

Correio eletrônico: olgavega@ufps. edu.co

** Ciências da Saúde (DeCS), na página http:// decs.bvs.br/E/ homepagee. $\mathrm{htm}$ Biblioteca Virtual em Saúde projeto BIREME, a Organização Mundial de Saúde e da Organização Panamericana da Saúde.
} 
ISSN 1794-9831

E-ISSN 2322-7028 Vol. 13 No. 1 Ene - Jun 2016 Cúcuta, Colombia

\section{Cuidadores y su competencia en la atención de sus familiares}

\section{RESUMEN}

Objetivo: describir el perfil sociodemográfico y competencia de los cuidadores familiares de personas afectadas por una enfermedad crónica. Materiales y Métodos: se realizó un estudio cuantitativo, descriptivo y transversal en 200 cuidadores familiares de enfermos crónicos, residentes del área de influencia de una institución prestadora de salud de primer nivel del Municipio de los Patios. En la medición de las características sociodemográfica fue utilizado el Instrumento Grupo de Cuidado al Paciente Crónico, Universidad Nacional, Cuidador, y en la valoración de la competencia el Instrumento Competencia para el Cuidado-Cuidador (Versión abreviada). Resultados: se describen las características sociodemográficas y de competencia en los participantes. Se encontró la mayor apreciación de los cuidadores en las categorías conocimiento, unicidad, instrumental y anticipación; más no en las dimensiones disfrutar y relaciones sociales e interacción. Conclusiones: reconocer la competencia como elemento imprescindible en el desempeño del cuidado, es un aspecto de consideración en la actuación profesional, de nuevas formas de abordaje de la persona y su cuidador.

PALABRAS CLAVE: cuidadores, enfermedad crónica, enfermería. 


\title{
Caregivers and competence in the care of their families
}

\begin{abstract}
Objective: to describe the demographic profile and competence of family caregivers of people affected with a chronic disease. Materials and Methods: a quantitative, descriptive cross-sectional study was conducted on 200 family caregivers of chronically ill residents of a catchment area health institution providing first level health care in the Los Patios municipality. In measuring the socio-demographic characteristics a Instrumento Grupo de Cuidado al Paciente Crónico, Universidad Nacional, Cuidador was used, and the assessment of competition, the Instrumento Competencia para el Cuidado-Cuidador (Abridged version). Results: sociodemographic and competition in the participating features are described. the greater appreciation of caregivers for knowledge, uniqueness, instrumental and anticipation categories found; but not in the dimensions of enjoyment, social relations and interaction. Conclusions: recognizing competence as an essential element in the performance of person bein cared for, is an aspect of consideration in profesional performance, new ways to approach the person and their caregiver.
\end{abstract}

KEY WORDS: caregivers, chronic disease, nursing. 
ISSN 1794-9831

E-ISSN 2322-7028

Vol. 13 No. 1

Ene - Jun 2016

Cúcuta, Colombia

\section{INTRODUÇÃO}

$\mathrm{O}$ relatório sobre a situação global das doenças não transmissíveis, a Organização Mundial de Saúde (OMS) declarou que o ser humano, as consequências sociais e económicas das doenças crónicas representam um dos maiores desafios do século atual. Dos 38 milhões de mortes registradas em 2012 para estes tipos de condições, mais de $40 \%$ deles (16 milhões) eram mortes prematuras antes de 70 anos de idade (1). Tendência semelhante com experiência em contexto latino-americano (2), nacional (3) e regional (4) para tomarem em ordem de importância como a principal causa de morte grupos, com um aumento considerável nos grupos etários mais velhos. Normalmente, estes tipos de doença em adultos mais velhos não são curáveis e, eventualmente, causar complicações que comprometem a independência e a autonomia de pessoas (2).

Mudanças no perfil demográfico e epidemiológico, são fatores que têm favorecido o aumento, também mudanças no estilo de vida associado com a globalização e aculturação ter contribuído para esta epidemia (5).

Os esforços para combater e controle tiveram um impacto negativo nas finanças dos sistemas de saúde. $\mathrm{O}$ aumento da procura de cuidados dessa população e as enormes quantidades de recursos necessários para o diagnóstico, tratamento e controle, têm gerado um aumento do consumo nos gastos públicos. Esta situação levou a carga para aumentar a famílias para prestar cuidados aos doentes em suas casas.

Não há consenso na literatura para indicar que a prestação de cuidados eficaz dos pacientes, e as qualificações dos profissionais de saúde é necessária; também tem se preocupado com a falta de formação e preparação destes para assumir essa responsabilidade (6) do mau desempenho da atenção básica (7) e o uso do conhecimento popular na prestação de cuidados (8).

Boykin e Shoenhoffer (9) referem que "a capacidade do cuidador varia de acordo com o seu grau de familiaridade com o contexto, o que significa que esta tem para o indivíduo ou a sociedade, ou seja, a diferença entre ver o cuidador como uma manifestação do sendo no mundo, para apreciar a importância de ser um cuidador ou obrigação de cuidar ".
Visto desta forma, cuidados competição representa a percepção do cuidador sobre a sua capacidade, habilidade, atitude e auto eficácia no desenvolvimento de suas ações e a implementação de medidas adequadas no momento adequado. De acordo com o Grupo de cuidados de doentes crônica a Universidade Nacional da Colômbia (10), descritos nos mesmos seis elementos: o conhecimento, singularidade, instrumental, desfrutar, antecipação, e a relação e interação social.

O conhecimento, representa o cuidador ideal, pensamentos ou crenças que você tem sobre os cuidados oferecidos, e influencia a sua capacidade de lidar de forma adaptativa às circunstâncias que surgem no cuidado diário. O segundo corresponde à singularidade, ele está seguindo a abordagem de Carrillo et al. (10), ambas as características internas e externas da personalidade, que são uma base fundamental para ser abordado de uma forma ou outra doença crónica e o papel como uma pessoa doente ou cuidador.

O terceiro, instrumental, são as ações de cuidados necessários para satisfazer as necessidades fisiológicas, tais como tomar banho, vestir, alimentação, eliminação, deambulação; essas atividades dependem da doença e incapacidade que o acompanham, como compromissos de manuseio, e obter serviços elementos necessários é adicionado (11).

No quarto elemento, bem-estar, está relacionado com a percepção das pessoas de acordo com suas próprias características pessoais, necessidades, satisfações, aspirações, expectativas e valores escalas aspectos do ambiente e das condições de vida globais. Antecipação corresponde ao quinto elemento, e é expressa na capacidade do cuidador para fornecer, em um possível curso de situações imprevistas forma atempada da doença como episódios de crise, emergência ou agravamento repentino da evolução clínica. O sexto e último elemento, o relacionamento e interação social, refere-se à conexão mútua estabelecido no domínio dos cuidados; através dele, o poyo exigido na resolução de problemas e lidar com situações difíceis é fornecido. Ele tem uma relação direta com o bem-estar psicológico do cuidador (12).

Enfermagem como uma disciplina profissional não pode estar longe deste problema, reconhecem 
os cuidadores como um elemento importante do sistema de cuidados de saúde na Colômbia requer identificar suas potencialidades e limitações nas ações tomadas por eles como reforço da sua competência. Daí a importância de indagar sobre aspectos do conhecimento, habilidade e atitude como indicadores básicos no desempenho dos profissionais de saúde e como uma exigência na qualidade dos cuidados prestados.

A produção de pesquisas na habilidade de cuidadores é considerável, mas não a competição. Na Colômbia, a capacidade dos profissionais de saúde tem sido descrita pela crônica Patient Care Grupo da Universidade Nacional da Colômbia, a região é o primeiro estudo realizado na medição específica da competência construção em cuidadores de pessoas em doença crônica.

\section{OBJETIVOS}

\section{Objetivo geral}

Identificar o perfil sócio demográfico dos cuidadores familiares de doentes crónicos e competência no atendimento.

\section{Objetivos específicos}

- Descrever sociodemographically cuidadores familiares de doentes crónicos.

- Descrever a concorrência cuidador cuidados de acordo com o conhecimento, singularidade, instrumental, desfrutar e avançar relação social e interação.

\section{MATERIAIS E MÉTODOS}

O estudo utilizou um desenho não-experimental, descritivo e quantitativo de corte transversal. A amostra foi intencional, e formou 200 cuidadores de adultos com doença crônica residentes na área de influência de uma das três agências de saúde da empresa estatal Social (ESE) Hospital local de Los Pátios, localizada no município de Los pátios, a leste do departamento de Norte de Santander (Colômbia), que serve de baixa complexidade em um nível de atenção primária.

Alguns dos cuidadores foram capturados no consultório da sua família; outros foram contatados em suas casas ou locais de residência. Em cada um dos cuidadores, a entrevista foi conduzida em particular e individualmente por assistentes estudantes de pesquisa previamente treinados em instrumentos de manipulação.

Os critérios de inclusão foram: residentes cuidadores na área de estudo influência, mais velho, cognitivamente intactas, que compartilhou a casa com o paciente e nenhum benefício económico das medidas adoptadas. Participantes que expressaram a sua recusa de participação voluntária foram excluídos.

Dois instrumentos foram aplicados, na caracterização dos prestadores de cuidados foi usado o Instrumento Grupo de Cuidado al Paciente Crónico, Universidad Nacional, Cuidador, (GCPC-UN-C) (13), por sua sigla em espanhol, o que significa: Cuidados De Grupo para Paciente Crônico, da Universidad Nacional, Cuidador; que permite a caracterização dos cuidadores familiares de pessoas com doenças crônicas não transmissíveis. Ele incorpora outros instrumentos, como os perfi PULSES, Teste SPMSQ e percepção do nível de perfil de carga.

O estudo considerou apenas o primeiro, PULSES, uma avaliação funcional criada por Moskowitz, expresso em seis funções $\mathrm{P}=$ estabilidade da doença ou condição física, $\mathrm{U}=$ uso de membros superiores, $\mathrm{L}=$ locomoção ou função dos membros inferiores, função sensorial $\mathrm{S}=\mathrm{e}=$ eliminação ou controle de esfíncteres, $\mathrm{S}=$ capacidade de socialização. Escala com 4 opções de acordo com o número do item. A interpretação é definida de acordo com três categorias: baixo disfunção 6 a 8 pontos, disfunção médio ou dependência de 9 a 11 e alta dependência do cuidador de 12 em diante a 24 , o que significa dependência total (14).

Na competição de medição foi utilizado instrumento para o Competencia para el Cuidado-Cuidador (Versão resumida) preparado pelo mesmo grupo académico (13). Ele contém 20 perguntas com graduação Likert de 1 a 4 que variam de quase nunca ou nunca, raramente, muitas vezes e quase sempre ou sempre. Seis categorias incluem: [C] Conhecimento (itens 1, 2, 3), [U] Unicidade (itens 4, 5, 6, 7), [i] instrumental (artigos 8, 9, 10), [D] Desfrute (itens 11, 12, 13, 14), [A] Antecipação (itens 15, 16), finalmente, [R] relações sociais e interação (itens 17, 18, 19, 20). Os instrumentos têm mostrado propriedades técnicas em 
ISSN 1794-9831

E-ISSN 2322-7028

Vol. 13 No. 1

Ene - Jun 2016

Cúcuta, Colombia termos de validade e confiabilidade adequadas para uso na Colômbia $(10,13)$.

A análise dos dados foi realizada com o uso de software estatístico Statistical Package for the Social Sciences (SPSS) versão 16.0 com estatísticas descritivas que foram gerados, identificando a categoria mais representativa em cada uma das variáveis analisadas; bem como a média, desvio padrão, valores mínimos e máximos. A análise percentual de cada item de categorias foi realizada pela escala de Likert de 1 a 4, em que 1 e 2 representam negativo, 3 e 4 avaliações equivalente a avaliação positiva.

A pesquisa considerou os padrões éticos nacionais (15-16) e internacionais (17) que fornecem proteção para os indivíduos como sujeitos experimentais. A participação voluntária dos participantes do estudo a formalização de consentimento informado foi garantida, ele teve a permissão para o uso de instrumentos, e com o aval do Comitê de Relacionamento Ensino-Serviço Hospital Local del Municipio de Los Patios para o desenvolvimento.

\section{RESULTADOS}

Informações cronicamente doente foi obtido globalmente para o banco de dados fornecido pelo hospital local durante os primeiros quatro meses de 2015. No processo de validação dos dados foi reportado como limitar a duplicação de informações, não endereço de correspondência e número de telefone, mudança de endereço, vive sozinho e sem carga; situação que reduziu o número da amostra participante.

\section{Perfil demográfico dos cuidadores}

Dos 200 participantes cuidadores $73,3 \%$ eram mulheres; a idade média foi de $63,5 \pm 14,6$ anos, variando entre 18 e 93 anos; $65 \%$ dos cuidadores tinham 60 anos ou mais velhos. Mal chegaram $71 \%$ em estudos primários incompleto ou completo. Com relação emocional estável em mais da metade dos participantes $(40 \%$ casados e coabitando $16,5 \%)$. Observou-se que $81,5 \%$ dos cuidadores são envolvidos em trabalhos domésticos, enquanto o trabalho de $12,5 \%$ informalmente e que $100 \%$ pertencem a um estrato e dois, o que corresponde a usuários com menos recursos económicos. Foram considerados todos os profissionais que participam de qualquer religião $(89,5 \%$ de católicos, $5 \%$ de cristãos, $4,5 \%$ de evangélicos, e ape- nas $1 \%$ SDA), com um nível médio de compromisso em $54 \%$ dos casos.

Ele mostrou que $86,5 \%$ gastam 24 horas por dia para cuidar de sua família; o tempo médio foi de $22 \pm 5$ horas por dia. Mais da metade dos destinatários dos cuidados $(62 \%)$ têm um único cuidador que o assiste; É em $56,5 \%$ dos casos as esposas (ou). O grau de funcionalidade medido pelo perfil de pulsos para as pessoas, relataram disfunção díade baixa ( $91 \%$ cuidadores, os receptores de cuidados de $80 \%$ ).

No que diz respeito à autoconhecimento e acessibilidade no uso da tecnologia da informação e comunicação (TIC), a maioria dos cuidadores expressar um nível baixo, principalmente no que diz respeito ao computador, telefone e internet (acima 75\%); 72,5\% dos participantes não expressa utilizar as TIC para apoiar os cuidados de sua família.

Coexistência foi relatado na díade (receptor de cuidados de cuidador) doença crônica, com hipertensão e diabetes mellitus as principais causas de morbidade desses (Tabela 1). 
Tabela 1. Características sociodemográficas dos cuidadores.

\begin{tabular}{|c|c|c|c|}
\hline VARIÀVEL & CATEGORIA & $\mathbf{n}(\%)$ & $\square \pm$ D.E \\
\hline Sexo & Feminino & $146(73 \%)$ & \\
\hline Idade & 60 ou mais anos & $130(65 \%)$ & $63.5 \pm 14.6$ \\
\hline Nível de educação & $\begin{array}{l}\text { Primàrio grau in- } \\
\text { completo }\end{array}$ & $108(54 \%)$ & \\
\hline Estado Civil & Casado(a) & $80(40 \%)$ & \\
\hline Ocupacao & Casa & $163(81,5 \%)$ & \\
\hline Religião & Católica & $178(89 \%)$ & \\
\hline Nível de compromisso religioso & Medio & $118(59 \%)$ & \\
\hline Socioeconómica Stratum & Um & $107(53,5 \%)$ & \\
\hline Cuidar da pessoa responsável a partir do momento do diagnóstico & SI & $181(90,5 \%)$ & \\
\hline Tempo tomado como um cuidador (meses & 120 meses ou menos & $146(73 \%)$ & $122 \pm 99.8$ \\
\hline Sitter única & SI & $124(62 \%)$ & \\
\hline \multirow{5}{*}{ Apoio com conta como zelador } & psicològico & $10(5 \%)$ & \\
\hline & Familiar & $66(33 \%)$ & \\
\hline & Religioso & $29(14,5 \%)$ & \\
\hline & Económico & $71(35,5 \%)$ & \\
\hline & Social & $74(37 \%)$ & \\
\hline Horas gastas diariamente no cuidado de sua família & 24 Horas & $173(86,5 \%)$ & $22 \pm 5$ \\
\hline Parentesco & Esposo(a) & $113(56,5 \%)$ & \\
\hline \multirow[t]{3}{*}{ Avaliação baixa cuidador PULSES } & Baja Disfunção & $182(91 \%)$ & \\
\hline & Media Disfunção & $17(8,5 \%)$ & \\
\hline & Alta Unidade & $1(0,5 \%)$ & \\
\hline \multirow[t]{3}{*}{ PULSES receptor de cuidado } & Baja Disfunção & $160(80 \%)$ & \\
\hline & Media Disfunção & $38(19 \%)$ & \\
\hline & Alta Unidade & $2(1 \%)$ & \\
\hline \multicolumn{4}{|l|}{ Auto-avaliação na utilização das TIC (nível de conhecimento) } \\
\hline Televisão & Alto & $100(50 \%)$ & \\
\hline Ràdio & Bajo & $71(35,5 \%)$ & \\
\hline Computador & Bajo & $177(88,5 \%)$ & \\
\hline Telefone & Bajo & $151(75,5 \%)$ & \\
\hline Internet & Bajo & $174(87 \%)$ & \\
\hline \multicolumn{4}{|l|}{ Auto-avaliação na utilização das TIC (Possibilidade de acesso) } \\
\hline Televisão & Mèdia & $80(40 \%)$ & \\
\hline Ràdio & Bajo & $111(55,5 \%)$ & \\
\hline Computador & Bajo & $175(87,5 \%)$ & \\
\hline Teléfone & Bajo & $161(80,5 \%)$ & \\
\hline Internet & Bajo & $172(86 \%)$ & \\
\hline Utilização das TIC para apoiar no cuidados & NO & $145(72,5 \%)$ & \\
\hline Percepção do nível de apoio com o uso das TIC no cuidado de sua família & Mèdia & $36(65,5 \%)$ & \\
\hline O TIC seria mais útil como um apoio no cuidado de sua família & No & $95(47,5 \%)$ & \\
\hline Diagnóstico Médico Cuidador & HTA & $144(72 \%)$ & \\
\hline Diagnóstico Médico Receptor 1 Cuidado & HTA & $137(68,5 \%)$ & \\
\hline
\end{tabular}

Fonte: Instrumento Grupo de Cuidado al Paciente Crónico, Universidad Nacional, Cuidador, (GCPC-UN-C), 2009. 
ISSN 1794-9831

E-ISSN 2322-7028 Vol. 13 No. 1

Ene - Jun 2016

Cúcuta, Colombia

\section{Competição para o care-cuidador}

Em relação ao conhecimento da categoria, a avaliação favorável dos participantes em todos os aspectos valorizados mostrou. Itens com melhor classificação (opções quase sempre ou sempre e frequentemente) correspondia, em sua ordem ao conhecimento referido pelos cuidadores sobre os sinais de alerta da doença que podem ocorrer (97\%), o monitoramento das condições de saúde seus pacientes $(92 \%)$, e a conclusão dos procedimentos exigidos pela pessoa a quem o cuidado $(98 \%)$.

$\mathrm{Na}$ avaliação positiva dimensão singularidade dos cuidadores, registrando a maior pontuação em todos os itens (opções quase sempre ou sempre e muitas vezes) também foi observado. Os participantes falaram sobre estabelecer o seu próprio plano de vida em $96 \%$ dos casos, ter confiança na sua capacidade para cuidar em casa $(95,7 \%)$; de ser capaz de simplificar as tarefas de atendimento $(95,5 \%)$ e facilmente superar sentimento de culpa ou raiva $(94,5 \%)$.

Em relação à categoria de aumento da apreciação instrumental de cuidadores com alta pontuação (opção quase sempre ou sempre e muitas vezes) em todos os itens encontrados. Mais ele se referiu aos cuidados de sua família organizar o apoio instrumental disponíveis, bem como administrar adequadamente os medicamentos prescritos, $98 \%$ para ambos os casos; e agindo de acordo com as recomendações prescritas $(97 \%)$.

No estudo, a avaliação negativa foi encontrado em dois dos quatro itens que compõem a categoria desfrutar. A população participante raramente reportados, raramente ou nunca $(50 \%$ e $15 \%$, respectivamente) foram satisfeitos com o seu estilo de vida atual. Também sobre a disponibilidade de tempo para as atividades de desenvolvimento pessoal, as respostas raramente, raramente ou nunca foram a maior parte atribuída pelos cuidadores $(37 \%$ e $24,5 \%$, respectivamente). No entanto, a grande maioria $(95,5 \%)$ relataram que sempre ou quase sempre e muitas vezes se sentem vital e com energia suficiente para atender as demandas de cuidados; também é surpreendente que uma percentagem considerável $(94,5 \%)$ relatou que o trabalho de cuidados deu-os em seu plano de vida.

Foi relatado na categoria força antecedência para encontrar a autoestima positiva na plenária dos itens. A maioria dos participantes relatou que quase sempre ou sempre e muitas vezes organiza os recursos disponíveis de forma eficiente para atender a pessoa que se importam (99\%), e também fornece as necessidades de gestão de risco e de saúde $(97,5 \%)$.

$\mathrm{Na}$ relação social categoria e avaliação negativa interação de um dos quatro itens achados composição. Cerca de mais de metade dos inquiridos algumas vezes, e raramente ou nunca $(40 \%$ e $10,5 \%$ dos casos) foram apoiados por outros membros da família para apoiar os cuidados. Como resultado positivo foi relatado que a maioria dos inquiridos considerou que sempre ou quase sempre, e muitas vezes procuram se comunicar efetivamente com a pessoa que você se importa, que têm fortalecido o vínculo de afeto com o seu receptor e se preocupam com a manutenção de tranquilidade emocional (98\%). 
Tabela 2. Distribuição percentual dos cuidadores como categorias do concurso (n: 200).

\begin{tabular}{|c|c|c|c|c|}
\hline Ítem & $\begin{array}{l}\text { Q u a s e } \\
\text { nunca ou } \\
\text { N u n c a } \\
(\%)\end{array}$ & $\begin{array}{l}\text { Raramente } \\
(\%)\end{array}$ & $\begin{array}{l}\text { Muitas ve- } \\
\text { zes (\%) }\end{array}$ & $\begin{array}{ll}\text { Quase sempre } \\
\text { ou } & \text { sempre } \\
(\%) & \end{array}$ \\
\hline \multicolumn{5}{|c|}{ CONHECIMENTO } \\
\hline $\begin{array}{l}\text { Eu sei como monitorar as condições de saúde da pessoa que } \\
\text { eu me importo }\end{array}$ & $1,5 \%$ & $6,5 \%$ & $21,0 \%$ & $71,0 \%$ \\
\hline $\begin{array}{l}\text { Eu sei como executar os procedimentos necessários a pes- } \\
\text { soa que se importa }\end{array}$ & $0,0 \%$ & $2,0 \%$ & $49,0 \%$ & $49,0 \%$ \\
\hline $\begin{array}{l}\text { Eu sei que os sinais de alerta da doença que pode apresentar } \\
\text { a pessoa de quem cuida }\end{array}$ & $0,0 \%$ & $3,0 \%$ & $24,5 \%$ & $72,5 \%$ \\
\hline \multicolumn{5}{|c|}{ UNICIDADE } \\
\hline Eu tenho confiança na minha capacidade de cuidar em casa & $0,5 \%$ & $3,5 \%$ & $31,2 \%$ & $64,5 \%$ \\
\hline sentimentos facilmente superou de culpa ou raiva & $0,0 \%$ & $5,5 \%$ & $45,5 \%$ & $49,0 \%$ \\
\hline Eu sou capaz de simplificar as tarefas de cuidado & $1,0 \%$ & $3,5 \%$ & $37,5 \%$ & $58,0 \%$ \\
\hline Eu estabeleço o meu próprio plano de vida & $0,0 \%$ & $4,0 \%$ & $36,5 \%$ & $59,5 \%$ \\
\hline \multicolumn{5}{|c|}{ APROVEITE } \\
\hline Estou satisfeito com o meu estilo de vida atual & $15 \%$ & $50,0 \%$ & $10,5 \%$ & $24,5 \%$ \\
\hline $\begin{array}{l}\text { Estou energia pena o suficiente para satisfazer as responsa- } \\
\text { bilidades de cuidados }\end{array}$ & $0,0 \%$ & $4,5 \%$ & $47,0 \%$ & $48,5 \%$ \\
\hline $\begin{array}{l}\text { Eu sinto que meu trabalho traz cuidador para meu próprio } \\
\text { plano de vida }\end{array}$ & $0,0 \%$ & $5,5 \%$ & $38,5 \%$ & $56,0 \%$ \\
\hline Tenho tempo para minhas atividades ou itens pessoais & $24,5 \%$ & $37,0 \%$ & $21,0 \%$ & $17,5 \%$ \\
\hline \multicolumn{5}{|c|}{ ANTECIPAÇÃO } \\
\hline $\begin{array}{l}\text { Organizar os recursos disponíveis de forma eficiente para } \\
\text { atender a pessoa que se importam }\end{array}$ & $0,0 \%$ & $1,0 \%$ & $47,5 \%$ & $51,5 \%$ \\
\hline $\begin{array}{l}\text { Prevejo de gestão e de saúde necessidades de risco para a } \\
\text { pessoa que você se importa }\end{array}$ & $0,5 \%$ & $2,0 \%$ & $24,5 \%$ & $73,0 \%$ \\
\hline \multicolumn{5}{|c|}{ RELACIONAMENTO SOCIAL E INTERAÇÃO } \\
\hline $\begin{array}{l}\text { Apoio conquista de outros membros da família para apoiar } \\
\text { os cuidados }\end{array}$ & $10,5 \%$ & $40,0 \%$ & $26,5 \%$ & $23,0 \%$ \\
\hline $\begin{array}{l}\text { Eu tento a pessoa que eu cuidar de tranquilidade emocional } \\
\text { segurar }\end{array}$ & $0,0 \%$ & $2,0 \%$ & $35,0 \%$ & $63,0 \%$ \\
\hline $\begin{array}{l}\text { Estou buscando efetivamente comunicar com a pessoa que } \\
\text { você se importa }\end{array}$ & $0,0 \%$ & $2,0 \%$ & $21,0 \%$ & $77,0 \%$ \\
\hline $\begin{array}{l}\text { Nós fortalecer o vínculo de afeto com a pessoa que você } \\
\text { se importa }\end{array}$ & $0,5 \%$ & $1,5 \%$ & $17,5 \%$ & $80,5 \%$ \\
\hline
\end{tabular}

Fonte: Instrumento Competencia para el Cuidado-Cuidador (Versão resumida), 2009. 
ISSN 1794-9831

E-ISSN 2322-7028 Vol. 13 No. 1

Ene - Jun 2016 Cúcuta, Colombia
Coexistência foi relatado na díade (receptor de cuidados de cuidador) doença crônica, com hipertensão e diabetes mellitus as principais causas de morbidade nestes; É coerente com outros estudos nacionais (18-19).

\section{DISCUSSÃO}

Sobre as características demográficas dos cuidadores semelhanças com outras publicações que estão na mesma linha são relatadas; a fêmea torna-se um papel de fator de cuidador decisivo, quando as circunstâncias socioculturais, e equipe foram alguns argumentos que legitimaram.

A participação de mais de sessenta cuidadores é realçado, os resultados que coincidem com outros estudos em diferentes contextos (20), onde a maioria deles estão em idade avançada foi destacada. Antes que observou que a idade do cuidador é aspecto fundamental dos efeitos negativos que os cuidados, como o seu impacto sobre o desenvolvimento da vida normal são exacerbados nos grupos etários mais velhos (21). Da mesma forma, a coexistência de doenças crônicas relatadas em participantes torna as condições de vulnerabilidade ainda mais crítica.

O nível educacional mais frequentemente referidos pelos cuidadores é baixa, com primário incompleto e analfabetismo na maioria dos casos; constatação de que reflete o nível de escolaridade da população do município dos pátios, onde início de abandono dos estudos são traços comuns desta geração de profissionais de saúde. Indicou que os cuidadores mais velhos e aqueles sem experiência de educação maior medida a falta de suficiente para fornecer o cuidado a concorrência (21).

Mais de metade da população era casado ou em coabitação, que mostra a relação que liga a díade (sujeito de cuidados de cuidador) e corresponde com outros estudos que indicaram o nexo de parentesco (consanguinidade ou afinidade) conectando-se ao recipiente de cuidado com o seu cuidador, e a relevância deste tipo de destino como um suporte na pessoa afetada e lidar com a doença crônica (22).

Em relação à ocupação, houve um predomínio de participantes que exercem trabalho doméstico e de trabalho independente. No longevo estudo, a condição sexo e idade encontrados são variáveis que poderiam explicar a ocupação exercida; e por isso é a característica desta região da fronteira colombianavenezuelana, onde ele está se tornando concentração notório de população deslocada, o exercício desempregado e informal, desfrute de aumento dos problemas sociais.

Todos os cuidadores disseram que praticar qualquer religião; a maior parte da população professa a religião católica; seguido pelo número de fiéis pertencentes aos cultos como evangélico, cristão e adventista em ordem, com um nível médio de compromisso. Eu encontrei semelhante ao relatado em um estudo em cinco regiões do país, onde uma percentagem representativa dos cuidadores mostrou a sua forte orientação religiosa com um grau médio de compromisso (23).

Trabalho neste campo (24) colher os benefícios da religiosidade das pessoas que recebem cuidados e aqueles que dar-lhe; No primeiro caso, os benefícios da crença religiosa baseiam-se na manutenção e recuperação da saúde do idoso como apoio à saúde. No segundo, constitui um componente que dá força $\mathrm{e}$ apoio para enfrentar as mudanças e incertezas geradas no atendimento, proporcionando direção e orientação ao cuidador em sua experiência.

No estudo a baixa funcionalidade dos doentes crónicos não se reflete na exigência de cuidados relatados em participantes, como o aumento no número de horas gasto, atenção às necessidades e prolongou o tempo no exercício do papel são achados em cuidadores.

A maioria dos inquiridos mostrou um baixo nível de conhecimento e acessibilidade, principalmente para computador, internet e celular (mais de 75\%); e que pode ser explicado pela fase que estas gerações viviam. Na literatura indicou que uma das dificuldades de acesso às novas tecnologias é devido a diferenças de idade e nível de escolaridade. Conforme aumenta a idade, o uso de novas tecnologias, como a diminuição da Internet e de computador; contrariamente às gerações atuais onde a inclusão em uma idade precoce da tecnologia nos sistemas de educação sobre o conhecimento natural, acesso e gestão.

A este respeito autores como Cuevas (23\%) oncordam em dizer que «é uma pessoa nascida na era da geração rádio, telefone fixo, e no início da televisão, e tem sido cautelosa e de uma distância respeitável os 
rápidos avanços na comunicação portanto, é algo que não é deles e que gera medo, apreensão [...] «. Tais argumentos explicar, na geração de cuidadores de adultos, não-uso e consideração de tal tecnologia como uma estratégia para apoiar a assistência prestada.

Quanto à concorrência, categoria de conhecimento a avaliação favorável dos cuidadores em todos os itens que o compõem foi encontrado para ser semelhante ao relatado em um estudo em que os participantes do estudo mostraram um alto nível de conhecimento (26). No entanto, indicou a importância de melhorar este aspecto, uma vez que foi reconhecido como limitando o cuidado oferecido. Para o autor, embora o conhecimento não é o único elemento necessário na competição de cuidadores para prestar cuidados é um componente essencial para alcançar e, portanto, para o desempenho eficaz das suas funções.

A propriedade singularidade e pessoal outro aspecto igualmente importante da competição solidária. Neste contexto, a avaliação positiva dos cuidadores, registrando a maior pontuação em todos os itens (opções quase sempre ou sempre e muitas vezes) foi observada. As percentagens mais elevadas constituíram aspectos, tais como: ter confiança na sua capacidade para cuidar em casa, o potencial de simplificar a sua tarefa, e o estabelecimento de seu próprio plano de vida. Constatação de que difere do encontrado em outras publicações (25) onde indicado o envolvimento deste aspecto.

Da mesma forma, a alocação de respostas positivas em todos os itens da dimensão instrumental foi encontrada. Cuidadores quase sempre ou sempre e muitas vezes agem seguindo as recomendações prescritas na pessoa carinhosa, instrumental organizar o apoio necessário e administrar adequadamente os medicamentos listados em sua família. Sendo um aspecto favorável dos participantes, uma vez a atenção para as recomendações em situações patológicas específicas como a realização prescrito pelas atividades da equipe interdisciplinar constitui uma necessidade que está permanentemente presente no processo de cuidado, e assumir a habilidade de cuidadores para fornecer os cuidados necessários em situações específicas da doença (27).

$\mathrm{Na}$ categoria desfrutando encontradas em cuidadores negativo autoestima em dois dos quatro itens que o constituem. A participantes percentuais significativos raramente reportados, raramente ou nunca se sentiram satisfeitos com o seu estilo de vida atual e disponibilidade de tempo para as atividades de desenvolvimento pessoal. Isto coincide com os achados de outros autores que relataram que altas demandas de cuidar de períodos de tempo, diariamente e de forma contínua, a carga percebida no cuidador torna-se evidente (21). No estudo das variáveis sócio demográfica corte e cuidar de cuidadores relataram explicar esses achados.

A avaliação favorável foi encontrada em todos os itens que compõem a categoria antecipação, cuidadores quase sempre ou sempre e muitas vezes fornecem as necessidades de gestão de saúde e de risco da pessoa que cuidar e organizar recursos para atendimento eficiente o paciente. É semelhante ao encontrado em um estudo recente (26). Estas características que envolvem a antecipação do que é feito, aplicar uma das várias formas de cuidados encaminhados por Ebersole e Hess (28) como cuidados antecipatória, compreendendo decisões com base nas necessidades futuras dos doentes crónicos, antecipação das necessidades inevitáveis influenciar as escolhas feitas no presente e tem um forte impacto sobre as ações do cuidador.

Quanto à categoria interpessoal relações envolvimento de um dos quatro itens encontrados; com a avaliação desfavorável, mais de metade dos inquiridos algumas vezes, e raramente ou nunca tiveram o apoio de outros membros da família para apoiar os cuidados. O que confirma a tendência observada em outros estudos (2223) que indicaram que não é significativamente maior sentido de um apoio limitado no grupo de cuidadores. Low apoio percebido recebida pelo cuidador tem sido descrito como um dos mais poderosos preditos de má qualidade de vida e os níveis de carga elevados (29).

\section{CONCLUSÕES}

Em relação às características sociodemográficas encontradas em cuidadores, semelhanças com outras publicações relatado. Corrobora entre outros, a presença de prioridade das mulheres na hierarquia dos cuidados, o parentesco (consangüinidade ou afinidade) que liga o cuidado receptor com seu cuidador, baixa escolaridade, inatividade no mercado de trabalho, a alta demanda em termos de frequência, intensidade e tempo no exercício do cuidado. Da 
ISSN 1794-9831

E-ISSN 2322-7028 Vol. 13 No. 1

Ene - Jun 2016

Cúcuta, Colombia mesma forma, eles são a única ajuda que recebe o recipiente de cuidado.

No estudo a avaliação favorável dos cuidadores relataram altos valores em marcando com dimensões, conhecimento, singularidade, instrumental e antecipação; no entanto, as categorias desfrutar e relações sociais e interação mostrou que o envolvimento em alguns dos itens que são coincidentes com outros estudos (30), que descreveram que os cuidados envolve uma série de transformações, que vão desde mudanças em suas vidas para o nível pessoal, família, trabalho e social. Achados pode estar relacionada com algumas variáveis e perfil sóciodemográfico dos cuidados relatados em participantes.

O impacto causado pelo fato de tomar cuidado em suporte de vida de trabalho de enfermagem do cuidador no reforço da sua competência como um prérequisito para o desempenho eficaz do seu trabalho. Igualmente necessária continuidade dos estudos, por quanto, é um assunto que exige uma investigação mais aprofundada.

\section{CONFLITO DE INTERESSES}

O autor declara não há conflito de interesse. 


\section{REFERÊNCIAS BIBLIOGRÁFICAS}

1. Organización Mundial de la Salud (OMS). Informe sobre la situación mundial de las enfermedades no transmisibles 2014. Ginebra: OMS [Internet]. 2014 [consultado 22 dic. 2015]. Disponível em: http://apps.who.int/iris/ bitstream/10665/149296/1/WHO_NMH_NVI_15.1_spa.pdf?ua=1

2. Menéndez J, Guevara A, Arcia N, León Díaz EM, Marín C, Alfonso JC. Enfermedades crónicas y limitación funcional en adultos mayores: estudio comparativo en siete ciudades de América Latina y el Caribe. Rev Panam Salud Pública 2005;17(5/6):353-61

3. Barrera-Ortiz L, Sánchez-Herrera B, Carrillo-González GM. La carga del cuidado en cuidadores de niños con enfermedad crónica. Rev Cubana Enfermer [Internet]. 2013 [consultado 23 dic. 2015]; 29(1): 39-47. Disponível em: http://scielo.sld.cu/scielo.php?script=sci_arttext\&pid=S0864-03192013000100006\&lng=es

4. Gobernación del Departamento de Norte de Santander. Diagnóstico de Salud. San José de Cúcuta: Gobierno Departamental; 2003.

5. Organización Panamericana de la Salud (OPS). Iniciativa Centroamericana de Diabetes (CAMDI): Encuesta de diabetes e hipertensión y factores de riesgo en enfermedades crónicas. Villa Nueva: Guatemala; 2006.

6. Carrillo G, Chaparro L, Sánchez B. Carga del cuidado en cuidadores familiares de personas con enfermedad crónica en la región pacífica colombiana. Cienc Enferm. [Internet]. 2014 [consultado 15 dic. 2015]; 20(2):83-91. Disponível em: http://www.scielo.cl/scielo.php?script=sci_arttext\&pid=S0717-95532014000200009\&lng=es

7. Luengo-Martínez CE, Araneda-Pagliotti G, López-Espinoza MA. Factores del cuidador familiar que influyen en el cumplimiento de los cuidados básicos del usuario postrado. Index Enferm. [Internet]. 2010 [consultado 9 dic. 2015]; 19(1):14-8. Disponível em: http://scielo.isciii.es/scielo.php?pid=S1132-12962010000100003\&script=sci arttext

8. Partezani R, Guimaraes $\mathrm{O}$, Marques S. Representaciones sociales del cuidado del anciano en trabajadores de salud en un ancianato. Latinoam Enferm. 2001 [Internet]. [consultado 19 ago. 2015]; 9(1):7-12. Disponível em: http://www.scielo.br/pdf/rlae/v9n1/11524.pdf

9. Boykin A, Shoenhoffer S. Nursing as caring: A model for transforming practice. Sudbury: Jones \& Bartlett; 2001. p. 2-5.

10. Carrillo GM, Sánchez-Herrera B, Arias-Rojas EM. Validation of an instrument to assess the homecare competency of the family caregiver of a person with chronic disease. Invest. Educ. Enferm. 2015; 33(3): 449-455.

11. Barrera-Ortiz L, Pinto-Afanador N, Sánchez-Herrera B, Carrillo GM, Chaparro-Díaz L. Cuidando en el hogar a personas con enfermedad crónica, su familia y cuidador. $1^{\text {a }}$ ed. Bogotá D.C.: Universidad Nacional de Colombia; 2010.

12. Herrera M, López M, Valencia C, Soto J, Lopera F, Wolf O, Rupprecht R. Autovaloración de calidad de vida y envejecimiento en adultos con riesgo de Alzheimer. Invest Educ Enferm. 2008;26(1):24-35.

13. Barrera L, Pinto N, Carrillo M, Chaparro L, Sánchez B. Cuidado a los cuidadores: familiares de personas con enfermedad crónica. Bogotá DC: Editorial de la Universidad Nacional Unibiblos; 2009.

14. Granger CV, Albrech GL, Hamilton BB. Outcome of Comprehensive Medical Rehabilitation messurement by pulses profile and the Barthel Index. Arch Physmed Rehabil 1979; 60: 145-54.

15. República de Colombia. Ministerio de Salud. Resolución 008430 por la cual se establece las normas académicas, técnicas y administrativas para la investigación en salud. Santa Fe de Bogotá: Ministerio de Salud; 1993.

16. República de Colombia. Tribunal Nacional ético de Enfermería, TNEE. Ley 911 de 2004, octubre 5, por el cual se dictan disposiciones en materia de responsabilidad deontológica para el ejercicio de la profesión de enfermería en Colombia; se establece el régimen disciplinar correspondiente y se dictan otras disposiciones. Bogotá D.C: El Abedul, Diario Oficial; 2004.

17. Asociación Médica Mundial (AMM). Declaración de Helsinki.Principios éticos para las investigaciones médicas en seres humanos. [Internet]. Paris: AMM; 2014 [Internet]. [consultado 26 dic. 2015]. Disponível em: http:// www.wma.net/es/30publications/10policies/b3/17c_es.pdf

18. Montalvo-Prieto AA, Cabrera-Nanclares B, Quiñones-Arrieta S. Enfermedad crónica y sufrimiento: revisión de literatura. Aquichan [Internet]. 2012 [consultado 11 ago. 2014]; 12(2):134-43. Disponível em: http://aquichan. unisabana.edu.co/index.php/aquichan/article/view/2120

19. González DS. Habilidad de cuidado de los cuidadores familiares de personas en situación de enfermedad crónica por diabetes Mellitus. Av de Enfermería. 2006; 24 (2):28-37.

20. Díaz-Alfonso H, Lemus-Fajardo NM, Gonzáles-Cosme W, Licort-Monduy OL, Gort-Cuba O. Repercusión ética del cuidador agotado en la calidad de vida de los ancianos. Rev Ciencias Médicas [Internet]. 2015 [consultado 31 dic. 2015]; 19(3): 478-490. Disponível em: http://scielo.sld.cu/scielo.php?script=sci_arttext\&pid=S1561- 
ISSN 1794-9831

E-ISSN 2322-7028 Vol. 13 No. 1 Ene - Jun 2016 Cúcuta, Colombia

$$
-31942015000300011 \& \operatorname{lng}=\mathrm{e}
$$

21. Rodríguez P. Mateo Echanagorria A. Sancho Castiello M. Cuidado a las personas mayores en los hogares españoles, el entorno familiar. Madrid: Ministerio de Trabajo y Asuntos Sociales; 2010.

22. Amaya-Ropero MC, Carrillo-González GM. Apoyo social percibido y afrontamiento en personas con dolor crónico no maligno. Aquichan 2015; 15(4): 461-474.

23. Corredor LR, Sánchez-Herrera B, Carrilo-González GM. Caracterización y carga del cuidado en hombres cuidadores familiares de personas con enfermedad crónica en Colombia. Archivos de Medicina. [Internet]. 2014 [consultado 31 dic. 2015]; 14: 219-230. Disponível em: http://www.redalyc.org/articulo.oa?id=273835711006

24. González-Valdés TL. Las creencias religiosas y su relación con el proceso salud-enfermedad. Revista Psicología Iztacala. [Internet]. 2004 [consultado 31 dic. 2015]; 7 (2): 19-29. Disponível em: http://www.iztacala.unam.mx/ carreras/psicologia/psiclin/principal.html

25. Cuevas F. Las Tics a la hora del café. Programa Sociedad de la información y el conocimiento. San José: Universidad de Costa Rica; 2012.

26. Carrillo-González GM, Barreto-Osorio RV, Arboleda LB, Gutiérrez-Lesmes OA, Melo BG, Ortiz VT. Competencia para cuidar en el hogar de personas con enfermedad crónica y sus cuidadores en Colombia. Rev. Fac. Med. 2015;63(4):665-75.

27. Instituto de Mayores y Servicios Sociales (IMSERSO). Modelo de centro de día para la atención a personas con enfermedad de Alzheimer. Serie Documentos Técnicos No. 21015. Madrid: ARTEGRAF, S.A; 2008.

28. Ebersole P, Hess P, eds. Toward healthy aging: human needs and nursing response. $5^{\text {a }}$ ed. St. Louis: Mosby; 1998.

29. Macedo EC, Rangel-Silva L, Paiva-Santos M, Pereira-Ramos MN. Sobrecarga y calidad de vida de madres de niños y adolescentes con enfermedad crónica: revisión integradora. Rev. Latino-Am. Enfermagem [Internet]. 2015 [consultado 4 ene. 2016]; 23(4): 769-777. Disponível em: http://www.scielo.br/scielo.php?pid=S0104$-11692015000400769 \&$ script $=$ sci_arttext\&tlng $=$ es

30. Moreira R, Turrini N. Paciente oncológico terminal: sobrecarga del cuidador. Enferm Glob. [Internet]. 2011 [consultado nov. 2015]; 10(22):1-8. Disponível em: http://scielo.isciii.es/scielo.php?script=sci_arttext\&pid=S1695$-61412011000200013 \& \operatorname{lng}=$ es 